\title{
Sub-acute toxicity study of a new aminoglycoside etimicin sulphate in swiss albino mice
}

\author{
Anurag Payasi, Manu Chaudhary, Ankush Gupta and Vivek Kumar Dwivedi \\ Office of Research Support, Venus Medicine Research Centre, Hill Top Industrial Estate, Bhatoli Kalan, \\ Baddi, H.P. - 173205, India
}

(Received January 30, 2010; Accepted March 19, 2010)

\begin{abstract}
Etimicin sulfate, an ethylization derivative of gentamicin, is a new soluble wide-spectrum synthetic aminoglycoside drug. It has wide antibacterial spectrum with high effect and less cross resistance as compared to other aminoglycosides. In order to further explore its safety and tolerance, we have conducted a subactute toxicity study on swiss albino mice. Results from the present study have elucidated that treatment of etimicin sulfate exerts no significant signs of toxicity at any dose level used in the study. Physiological as well as hematological parameters were unaltered throughout the study. Biochemical examination and histopathology of all organs confirmed no significant alteration at any dose levels. The result of this study has suggested there was no obvious toxicity observed with the treatment of etimicin sulphate. It was found to be a safe alternative for various severe infections.
\end{abstract}

Key words: Aminoglycosids, Etimicin, Bacterial infections, Sub-acute

\section{INTRODUCTION}

Aminoglycosides are a group of broad-spectrum antibiotics that are effective to treat infections caused by gram-negative bacteria (Sundin et al., 2001). These are potent bactericidal antibiotics and particularly active against aerobic, gram-negative bacteria and act synergistically against certain gram-positive organisms (Wang et al., 2002). Aminoglycosides are used in the treatment of severe infections of the abdomen and urinary tract, as well as bacteremia and endocarditis (Gonzalez and Spencer, 1998). Among aminoglycosides, etimicin sulphate is a semi-synthetic aminoglycoside antibiotic with broad spectrum for parenteral administration. It is the newest generation of the antibiotic aminoglycoside family (Gilbert, 1995; Montie and Patamasucon, 1995; Edson and Terrell, 1991). It acts by interfering with the synthesis of microbial protein, while the synthesis of nucleic acid is not affected and has good anti bacterium effect on most gram positive bacteria and gram negative bacteria and it has high efficacy and safety, and less cross resistance (Lortholary et al., 1995; Karlowsky et al., 1997; Neu, 1992). In vivo antibacterial study indicates that etimicin is more potent than gentamicin, amikacin and tobramycin, and similar to netilmicin (Xi et al., 2006; Zhao et al.,
2000). Available reports suggest that etimicin is found to be sensitive on gentamicin resistant bacteria including Staphylococcus aureus and methicillin resistant bacteria Staphyloccus aureus (MRSA) (Zhao et al., 2000; Huy and Deffrennes, 1988). But ototoxicity and nephrotoxicity of aminoglycosides have limited their clinical applications (Choudhury and Ahmed, 1997). To overcome these issues a new aminoglycoside, etimicin, was introduced (Hock and Anderson, 1995). Etimicin sulfate is a potential new aminoglycoside antibiotic (Hock and Anderson, 1995; Vogelman and Craig, 1986).

Being a new drug, limited information is available on the toxicity and safety profile of this potential drug. We therefore investigated whether etimicin sulphate treatment is associated with any kind of toxicities in preclinical setting using mice as an experimental model.

\section{MATERIALS AND METHODS}

\section{Animals \\ Totally forty eight healthy swiss albino mice (males and females, weight 25-30 g) were selected for the present study. All animals were divided into four groups (three treatment groups and one control group). Animals were given with Nutrilab brand extruded pelleted mouse feed}

Correspondence: Anurag Payasi (E-mail: vivekdwivedi@venusremedies.com) 
(Tetragon Chemie, Pvt. Ltd., Bangalore, India) and portable water ad libitum. The institutional animal ethics committee for toxicological studies, Pune, India had approved the study protocol.

\section{Experimental design and drug treatment}

Mice were housed in polycarbonate cages (6 in each) at controlled room temperature of $27-29^{\circ} \mathrm{C}$ and a relative humidity between 30 to $70 \%$ with a constant light-dark schedule (12 hr light and $12 \mathrm{hr}$ dark cycle). Each group contains 6 male and 6 female mice as given below:

Group I : Control normal saline treated group ( $0.9 \%$ $\mathrm{NaCl}$ )

Group II : Treated with etimicin sulphate (50 $\mathrm{mg} / \mathrm{kg}$ body weight)

Group III : Treated with etimicin sulphate $(100 \mathrm{mg} / \mathrm{kg}$ body weight)

Group IV : Treated with etimicin sulphate $(200 \mathrm{mg} / \mathrm{kg}$ body weight)

Etimicin sulphate was dissolved in $0.9 \% \mathrm{NaCl}$ and administered into the mice at three dose levels i.e. $50 \mathrm{mg} /$ $\mathrm{kg}$ body weight, $100 \mathrm{mg} / \mathrm{kg}$ body weight and $200 \mathrm{mg} /$ $\mathrm{kg}$ body weight corresponding to low dose, intermediate dose and high dose, respectively for twenty eight days treatment. Drug was given intravenously daily once a day for 28 days according to their body weight. Physiological parameters (body weight, food and water intake) and local injury were studied throughout the treatment. Mortality if any, in all of the groups, during the course of treatment was also recorded. Autopsy was done if mice died during the course of treatment. At the end of treatment, overnight fasted animals were sacrificed, blood and tissues samples were collected on 29th day. Haematological and biochemical and histological parameters were studied. The organs were quickly blotted, weighed on digital balance and processed for histological studies.

\section{Hematological and biochemical parameters}

Blood was collected into polypropylene tube containing $3.8 \%$ sodium citrate by cardiac puncture. Blood samples were analysed for routine haematological parameters. Blood cell count was determined with blood smears. Hemogram was investigated on ACT diff-2 Hematolgy Analyzer (Beckman Coulter India, Ltd., Mumbai, India). Biochemical parameters were investigated in serum sample. Serum glutamic oxaloacetic transaminase (SGOT), serum glutamic pyruvic transaminase activities (SGPT), serum alkaline phosphatase (SAP), total protein, blood urea nitrogen (BUN) and blood sugar levels were estimated. All parameters were studied by Merck semi auto analyzer by using Merck analytical kits.

\section{Histological examinations}

Liver, kidneys, stomach, heart and lungs were removed from the sacrificed animals and were preserved in $10 \%$ buffered formalin for histological examination.

\section{Statistical analysis}

The representing data are shown as mean \pm S.D. Dunnett test was performed for the evaluation of data. $p>$ 0.05 was considered as non significant.

\section{RESULTS}

\section{Physiological parameters}

There were no significant changes in physical behaviors throughout the experimental period. The body weight of all treated groups was not altered significantly as compared with control normal saline treated group (Fig. 1).

\section{Hematology}

In all treated groups (male and female groups), there was not any significant alteration observed in hemoglobin $(\mathrm{Hb})$, red blood cell counts (RBC), white blood cell (WBC) counts, platelet counts, Reticulocyte (Rt), hematocrit (HCT), mean corpuscular volume (MCV), mean cell haemoglobin $(\mathrm{MCH})$, mean cell corpuscular hemoglobin concentration (MCHC) as compared to the control group (Tables 1 and 2).

\section{Biochemical parameters}

In male and female groups, no significant changes in SGOT and SGPT activities were observed in all the treated groups as compared to control group. The levels of serum proteins and blood sugar levels were not changed in all groups in comparison to the control group (Tables 1 and 2). There was a slight increase in SAP level at high dose level Etimicin group in female mice.

\section{Histological examination}

In histological analysis, there were not any treatmentrelated changes grossly and histopathologically upto the dose of $200 \mathrm{mg} / \mathrm{kg}$ were observed.

\section{DISCUSSION}

Use of Aminoglycoside compound is limited in the clinical practices due to side effects of ototoxicity and nephrotoxicity (Sundin et al., 2001; Wang et al., 2002; Wang et al., 1995). In order to resolve these issues related to toxicity, a new aminoglycoside was successfully developed and named etimicin sulfate (Bailey et al., 1997). Etimicin is active against most strains of the gram positive 


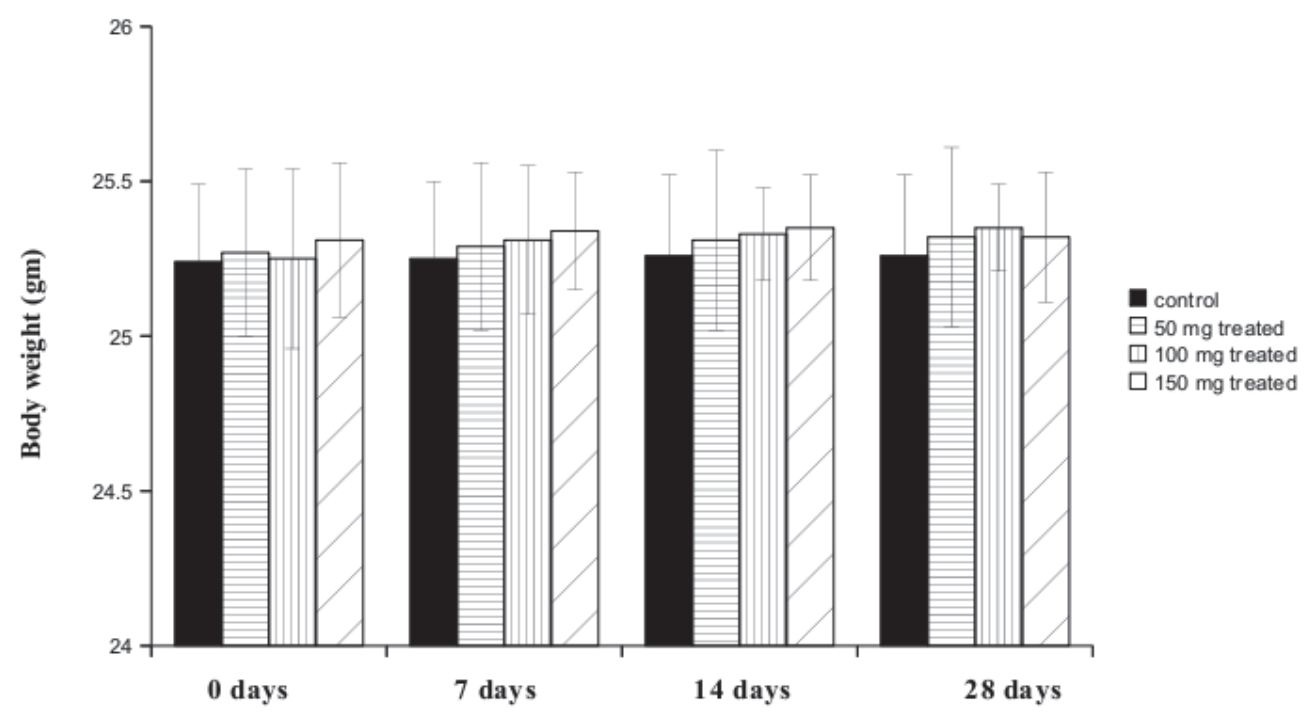

Fig. 1. Status of body weight in different concentration of paracetamol treated groups. Values are represented in mean \pm S.D. Each group of body weight was measured perday for 28th days.

and gram negative bacteria (Hatala et al., 1997; Freeman and Strayer, 1996). In vitro studies using etimicin showed that this drug had the advantage of broad spectrum activity with high efficacy and less cross resistance as well as higher sensitivity to enterobacter (Ferriols-Lisart and Alos-Alminana, 1996). Caiyun et al. (2000) conducted a clinical trial on etimicin and reported a low rate of adverse reaction. In the present study, no physiological changes were observed during the study period of twenty eight days in all three etimicin sulphate treatment groups as compared to control. Body growth and an increase in body weights of treated animals of each sex were of similar pattern as in the control group.

The kidney damage could be due to lesser efficacy and high dose of aminoglycosides (Wang et al., 2002; Ali and Goetz, 1997). The studies of pre-clinical pharmacology and toxicology showed low ototoxicity and nephrotoxicity and this drug is active against some pathogens which are resistant to other aminoglycosides (Li et al., 1995; Wang et al., 1995). However, kidney function related parameters were evaluated in the present study and no significant differences were observed in BUN, glucose and proteins compared with the control (Tables 3 and 4). Yalin et al. (2006) also reported that there is no marked renal toxicity of etimicin plus other antibacterial in the treatment of elderly patients with severe pneumonia.

Blood was evaluated for hematological toxicity of etimicin sulphate. Hemogram was estimated and results showed no significant changes on blood cell count and haemoglobin. The $\mathrm{MCH}$ and $\mathrm{MCHC}$ in etimicin sulphate treated group were similar to control. $\mathrm{MCV}$ was observed slightly lower at a maximum dose in both sexes, but was statistically insignificant (Tables 1 and 2).

Aminogycosides are known to cause hepatotoxicity by increasing the activity liver enzymes (Nisly et al., 2007). To evaluate effect of etimicin on liver function, specific parameters of liver were estimated. It was found that etimicin sulphate did not alter SAP, SGOT and SGPT activities, which confirmed no hepatotoxicity by etimicin sulphate treatment of each sex as compared to the control group (Tables 3 and 4). Lindblad et al. (1994) also reported that high doses of aminoglycosides did not produce liver toxicity in patients with cystic fibrosis. Histopathological analysis showed no signs of toxicity in any of the organs in treatment groups as compared to the control group. Thus histopathological studies also confirmed the safety data, along with other physiological, biochemical and heamatological parameters after etimicin sulphate treatment.

In conclusion, our results provide the safety profile of this potential drug. The data suggest that etimicin sulfate is an effective safe antibiotic and is considered to be used widely at the clinical application. 
A. Payasi et al.

Table 1. Effect of sub acute dose of Etimicin on hemogram in male mice

\begin{tabular}{|c|c|c|c|c|}
\hline Parameters & Control & $\begin{array}{l}\text { Etimicin } \\
50 \mathrm{mg} / \mathrm{kg}\end{array}$ & $\begin{array}{l}\text { Etimicin } \\
100 \mathrm{mg} / \mathrm{kg}\end{array}$ & $\begin{array}{c}\text { Etimicin } \\
200 \mathrm{mg} / \mathrm{kg}\end{array}$ \\
\hline Haemoglobin (g\%) & $17.08 \pm 1.16$ & $16.80 \pm 1.35$ & $17.23 \pm 1.22$ & $16.02 \pm 1.80$ \\
\hline Total RBC (X106/cmm) & $6.18 \pm 1.20$ & $5.85 \pm 1.51$ & $6.08 \pm 0.78$ & $5.95 \pm 0.67$ \\
\hline Rt (\%) & $1.28 \pm 0.23$ & $1.19 \pm 0.22$ & $1.32 \pm 0.43$ & $1.18 \pm 0.54$ \\
\hline HCT (\%) & $50.0 \pm 4.10$ & $49.55 \pm 4.62$ & $50.33 \pm 3.81$ & $48.38 \pm 5.48$ \\
\hline $\operatorname{MCV}\left(\mu \mathrm{m}^{3}\right)$ & $83.47 \pm 16.67$ & $84.31 \pm 23.63$ & $83.98 \pm 12.96$ & $84.22 \pm 14.38$ \\
\hline $\mathrm{MCH}(\mathrm{pg})$ & $28.53 \pm 5.67$ & $28.65 \pm 8.24$ & $28.76 \pm 4.53$ & $27.18 \pm 5.74$ \\
\hline $\mathrm{MCHC}(\%)$ & $34.56 \pm 0.58$ & $33.93 \pm 0.27$ & $34.94 \pm 0.38$ & $33.94 \pm 0.57$ \\
\hline Platelets (X105/cmm) & $8.42 \pm 0.85$ & $7.80 \pm 0.97$ & $8.60 \pm 1.11$ & $8.40 \pm 0.88$ \\
\hline Total WBC (X103/cmm) & $5.87 \pm 1.02$ & $5.95 \pm 1.51$ & $5.75 \pm 0.99$ & $5.97 \pm 1.22$ \\
\hline \multirow{4}{*}{ Differential \% } & $19.33 \pm 2.16$ & $20.50 \pm 1.87$ & $20.17 \pm 1.33$ & $19.83 \pm 2.86$ \\
\hline & $78.17 \pm 3.06$ & $77.17 \pm 1.47$ & $76.67 \pm 1.63$ & $78 \pm 3.16$ \\
\hline & $1.83 \pm 1.17$ & $1.83 \pm 0.98$ & $2.17 \pm 0.98$ & $1.67 \pm 0.82$ \\
\hline & $0.67 \pm 0.52$ & $0.50 \pm 0.55$ & $1.00 \pm 0.63$ & $0.50 \pm 0.55$ \\
\hline
\end{tabular}

Values are presented in mean \pm S.D. ( $\mathrm{n}=6$ in each group). Data was analyzed by Dunett test between control vs all treated groups. $\mathrm{p}>0.05$ considered not significant (ns). $\mathrm{E}=$ Eosiniophils, $\mathrm{L}=$ Leukocytes, $\mathrm{M}=$ Monocytes, $\mathrm{N}=$ Neutrophils.

Table 2. Effect of sub acute dose of Etimicin on hemogram in female mice

\begin{tabular}{|c|c|c|c|c|c|}
\hline \multicolumn{2}{|l|}{ Parameters } & Control & $\begin{array}{l}\text { Etimicin } \\
50 \mathrm{mg} / \mathrm{kg}\end{array}$ & $\begin{array}{c}\text { Etimicin } \\
100 \mathrm{mg} / \mathrm{kg}\end{array}$ & $\begin{array}{c}\text { Etimicin } \\
200 \mathrm{mg} / \mathrm{kg}\end{array}$ \\
\hline \multicolumn{2}{|c|}{ Haemoglobin (g\%) } & $17.17 \pm 0.85$ & $16.68 \pm 1.43$ & $17.42 \pm 1.32$ & $17.03 \pm 1.17$ \\
\hline \multicolumn{2}{|c|}{ Total RBC (X10\%/cmm) } & $5.82 \pm 1.00$ & $5.48 \pm 0.98$ & $5.75 \pm 0.93$ & $6.02 \pm 1.23$ \\
\hline \multicolumn{2}{|l|}{ Rt (\%) } & $1.32 \pm 0.22$ & $1.25 \pm 0.15$ & $1.68 \pm 0.71$ & $1.32 \pm 0.27$ \\
\hline \multicolumn{2}{|l|}{ HCT (\%) } & $50.88 \pm 3.43$ & $44.80 \pm 4.38$ & $51.95 \pm 4.48$ & $48.45 \pm 5.32$ \\
\hline \multicolumn{2}{|l|}{$\operatorname{MCV}\left(\mu \mathrm{m}^{3}\right)$} & $89.52 \pm 15.53$ & $88.15 \pm 14.57$ & $91.40 \pm 11.30$ & $88.56 \pm 15.69$ \\
\hline \multicolumn{2}{|l|}{$\mathrm{MCH}(\mathrm{pg})$} & $30.23 \pm 5.41$ & $28.38 \pm 4.40$ & $30.68 \pm 3.25$ & $28.67 \pm 5.41$ \\
\hline \multicolumn{2}{|l|}{$\mathrm{MCHC}(\%)$} & $33.75 \pm 0.41$ & $34.07 \pm 0.70$ & $33.55 \pm 0.57$ & $33.90 \pm 0.72$ \\
\hline \multicolumn{2}{|c|}{ Platelets $\left(\mathrm{X} 10^{5} / \mathrm{cmm}\right)$} & $8.53 \pm 1.15$ & $8.73 \pm 0.63$ & $8.02 \pm 0.92$ & $8.25 \pm 1.27$ \\
\hline \multicolumn{2}{|c|}{ Total WBC (X103/cmm) } & $5.42 \pm 0.96$ & $5.83 \pm 1.19$ & $5.77 \pm 0.80$ & $5.57 \pm 1.04$ \\
\hline \multirow{4}{*}{ Differential \% } & $\mathrm{N}$ & $19.67 \pm 3.33$ & $18.81 \pm 2.94$ & $19.33 \pm 3.98$ & $17.83 \pm 3.49$ \\
\hline & $\mathrm{L}$ & $78 \pm 2.76$ & $80.17 \pm 2.99$ & $78.17 \pm 4.40$ & $80.00 \pm 3.10$ \\
\hline & $\mathrm{E}$ & $1.67 \pm 0.82$ & $1.50 \pm 1.05$ & $2.00 \pm 0.89$ & $1.50 \pm 1.05$ \\
\hline & M & $0.67 \pm 0.52$ & $0.67 \pm 0.52$ & $0.50 \pm 0.55$ & $0.67 \pm 0.52$ \\
\hline
\end{tabular}

Values are presented in mean \pm S.D. ( $\mathrm{n}=6$ in each group). Data was analyzed by Dunett test between control $v s$ all treated groups. $\mathrm{p}>0.05$ considered not significant (ns). $\mathrm{E}=$ Eosiniophils, $\mathrm{L}=$ Leukocytes, $\mathrm{M}=$ Monocytes, $\mathrm{N}=$ Neutrophils. 
Sub-acute toxicity of etimicin

Table 3. Effect of sub acute dose of Etimicin on biochemical parameters in male mice

\begin{tabular}{lcccc}
\hline & Control & Etimicin & Etimicin & Etimicin \\
& $50 \mathrm{mg} / \mathrm{kg}$ & $100 \mathrm{mg} / \mathrm{kg}$ & $600 \mathrm{mg} / \mathrm{kg}$ \\
\hline Total protein (g\%) & $6.42 \pm 2.21$ & $5.73 \pm 1.13$ & $6.02 \pm 1.12$ & $6.33 \pm 0.93$ \\
BUN (mg\%) & $22.33 \pm 3.83$ & $21.33 \pm 3.27$ & $22.50 \pm 3.73$ & $19.67 \pm 3.50$ \\
SGPT (IU/l) & $49.50 \pm 2.43$ & $48.17 \pm 3.71$ & $48.50 \pm 1.87$ & $49.83 \pm 5.12$ \\
SGOT (IU/l) & $95.83 \pm 9.60$ & $93.33 \pm 13.62$ & $89.00 \pm 14.75$ & $88.43 \pm 6.34$ \\
SAP (IU/l) & $241.50 \pm 56.26$ & $235.17 \pm 52.98$ & $237 \pm 39.00$ & $240.81 \pm 56.12$ \\
Blood Sugar (mg\%) & $100.83 \pm 12.98$ & $91.67 \pm 8.09$ & $102.17 \pm 6.14$ & $97.00 \pm 6.99$ \\
\hline
\end{tabular}

Values are presented in mean \pm S.D. ( $\mathrm{n}=6$ in each group). Data was analyzed by Dunett test between control $v s$ all treated groups. $\mathrm{p}>0.05$ considered not significant (ns).

Table 4. Effect of sub acute dose of Etimicin on biochemical parameters in female mice

\begin{tabular}{lcccc}
\hline & Control & $\begin{array}{c}\text { Etimicin } \\
50 \mathrm{mg} / \mathrm{kg}\end{array}$ & $\begin{array}{c}\text { Etimicin } \\
100 \mathrm{mg} / \mathrm{kg}\end{array}$ & $\begin{array}{c}\text { Etimicin } \\
200 \mathrm{mg} / \mathrm{kg}\end{array}$ \\
\hline Total protein (g\%) & $6.47 \pm 1.18$ & $6.22 \pm 1.15$ & $6.32 \pm 0.99$ & $8.17 \pm 0.86$ \\
BUN (mg\%) & $20.17 \pm 2.40$ & $21.50 \pm 3.08$ & $21.83 \pm 2.48$ & $20.83 \pm 4.26$ \\
SGPT (IU/l) & $49.83 \pm 7.05$ & $52.83 \pm 5.95$ & $51.17 \pm 6.88$ & $53.50 \pm 7.45$ \\
SGOT (IU/l) & $94.00 \pm 7.10$ & $100.33 \pm 14.90$ & $98.33 \pm 15.21$ & $91.50 \pm 7.06$ \\
SAP (IU/l) & $236.34 \pm 44.28$ & $234.37 \pm 44.33$ & $238.46 \pm 18.38$ & $243.85 \pm 58.44$ \\
Blood Sugar (mg\%) & $95.0 \pm 6.74$ & $95.83 \pm 9.66$ & $98.33 \pm 8.87$ & $98.17 \pm 7.25$ \\
\hline
\end{tabular}

Values are presented in mean \pm S.D. ( $\mathrm{n}=6$ in each group). Data was analyzed by Dunett test between control $v s$ all treated groups. $\mathrm{p}>0.05$ considered not significant (ns).

\section{ACKNOWLEDGMENT}

Authors are thankful to management of Venus Medicine Research Centre for providing infrastructure and necessary grant for carrying out this study.

\section{REFERENCES}

Ali, M.Z. and Goetz, M.B. (1997): A meta-analysis of the relative efficacy and toxicity of single daily dosing versus multiple daily dosing of aminoglycosides. Clin. Infect. Dis., 24, 796-809.

Bailey, T.C., Little, J.R., Littenberg, B., Reichley, R.M. and Dunagan, W.C. (1997): A meta-analysis of extended-interval dosing versus multiple daily dosing of aminoglycosides. Clin. Infect. Dis., 24, 786-795.

Caiyun, Z., Jiatai, L.I., Jie, H., Min, G.U.O., ye, Z. and Yifang, C. (2000): A randomized controlled clinical trial on etimicin, a new aminoglycoside antibiotic versus netilmicin in the treatment of bacterial infection. Chin. Med. J., 113, 1026-1030.

Choudhury, D. and Ahmed, Z. (1997): Drug-induced nephrotoxicity. The Med. Clin. North Ame., 81, 705-717.
Edson, R.S. and Terrell, C.L. (1991): The aminoglycosides. Mayo Clin. Proc., 66, 1158-1164.

Ferriols-Lisart, R. and Alos-Alminana, M. (1996): Effectiveness and safety of once-daily aminoglycosides: a meta-analysis. Amer. J. Health Sys. Phar., 53, 1141-1150.

Freeman, C.D. and Strayer, A.H. (1996): Mega-analysis of metaanalysis: an examination of meta-analysis with an emphasis on once-daily aminoglycoside comparative trials. Pharmacotherapy, 16, 1093-1102.

Gilbert, D.N. (1995): Aminoglycosides. In: Principles and practice of infectious diseases (Mandell, G.L., Bennett, J.E. and Dolin, R., eds.), pp.279-301, Douglas \& Bennett's, Churchill, Livingston, New York.

Gonzalez, L.S. 3rd and Spencer, J.P. (1998): Aminoglycosides: a practical review. Am. Fam. Physician, 58, 1811-1820.

Hatala, R., Dinh, T.T. and Cook, D.J. (1997): Single daily dosing of aminoglycosides in immunocompromised adults: a systematic review. Clin. Infect. Dis., 24, 810-815.

Hock, R. and Anderson, R.J. (1995): Prevention of drug-induced nephrotoxicity in the intensive care unit. J. Crit. Care, 10, 33-43.

Huy, B.T.P. and Deffrennes, D. (1988): Aminoglycoside ototoxicity: influence of dosage regimen on drug uptake and correlation 
A. Payasi et al.

between membrane binding and some clinical features. Acta. Otolaryngol., 105, 511-515.

Karlowsky, J.A., Zelenitsky, S.A. and Zhanel, G.G. (1997): Aminoglycoside adaptive resistance. Pharmacotherapy, 17, 549555.

Lindblad, A., Hultcrantz, R. and Strandvik, B (1994): High doses of aminoglycosides did not produce liver toxicity in patients with cystic fibrosis. J. Hepatol., 20, 201-205.

Li, Q.X., Fang, Y.Y. and Sun, J.H. et al. (1995): Ototoxicity of antibiotic 89-07 with gentamicin and amikacin. Chin. J. Antibiot., 20, 442-447.

Lortholary, O., Tod, M., Cohen, Y. and Petitjean, O. (1995): Aminoglycosides. Med. Clin. North Am., 79, 761-787.

Montie, T. and Patamasucon, P. (1995): Aminoglycosides: the complex problem of antibiotic mechanisms and clinical applications. Eur. J. Clin. Microbiol. Infect. Dis., 14, 85-87.

Neu, H.C. (1992): The crisis in antibiotic resistance. Science, 257, 1064-1073.

Nisly, S.A., Ray, S.M., Moye, R.A., Soler, E.M. and larouche, M. (2007): Tobramycin-induced hepatotoxicity. Ann. Pharmacother., 41, 2061-2065.

Sundin, D.P., Sandoval, R. and Molitoris, B.A. (2001): Gentamicin inhibits renal protein and phospholipid metabolism in rats: implications involving intracellular trafficking. J. Am. Soc. Nephrol., 12, 114-123.

Vogelman, B. and Craig, W.A. (1986): Kinetics of antimicrobial activity. J. Pediatr., 108, 835-840.

Wang, H.X., Zhang, L.R., Ma, X.C. and Ma,T.X. (2002): Influence of piperacillin on pharmacokinetics of etimicin in healthy volunteers. Acta Pharmacol. Sinica, 23, 376-380.

Wang, P.Y., Li, X.Q. and Fang, Y.Y. et al. (1995): Ototoxicity of antibiotic 89-07 and netil micin in guinea. Chin. J. Antibiot., 20, 448-454.

Xi, L., Wu, G. and Zhu, Y. (2006): Analysis of etimicin sulfate by liquid chromatography with pulsed amperometric detection. J. Chromatogr. A, 1115, 202-207.

Yalin, L., Yan, Z., Hui, T., Xiaoyu, L., Changyi, S. and Jian, Q. (2006): Effect of etimicin plus other antibacterial on renal function in elderly patients with severe pneumonia. ADRJ, 6, 428430.

Zhao, C., Li, J., Hou, J., Guo, M., Zhang, Y. and Chen, Y. (2000): A randomized controlled clinical trial on etimicin, a new aminoglycoside antibiotic, versus netilmicin in the treatment of bacterial infections. Chin. Med. J., 113, 1026-1030. 